\title{
A TRADUÇÃO DO TEXTO TEATRAL: PERFORMANCES DE UMA POÉTICA
}

\section{THE TRANSLATION OF THE THEATER TEXT: PERFORMANCES OF A POETIC}

Rodrigo Ielpo

Universidade Federal do Rio de Janeiro Rio de Janeiro, Rio de Janeiro, Brasil

RESUMO: Para que a tradução do texto de teatro não perca de vista suas especificidades, é preciso levar em conta todos os elementos de ordem cênica que devem atravessá-la. Essa operação acaba por evocar a condição iterável particularmente sensível nos textos teatrais, os quais devem colocar literalmente em cena o traço citacional que os mobiliza desde o princípio, permitindo, assim, que continuem a funcionar em tempos e espaços completamente distintos daquele em que a peça foi redigida. O objetivo desse artigo é pensar as formas como esse "gênero" de tradução, ao atualizar as potências performativas dos textos a partir da noção de teatralidade, acaba por ecoar uma dimensão ético-estética presente nos pressupostos de certa crítica descrita por Walter Benjamin em $O$ conceito de Crítica de Arte no Romantismo Alemão. PALAVRAS-CHAVE: Tradução; Teatro; Iterabilidade; Performatividade

\begin{abstract}
In order for the translation of theatrical texts not to cause their specificities to be lost, it is necessary to take into account all the scenic elements that should compose it. This operation evokes the iterative condition of drama texts which mobilizes them from the beginning, thus allowing the play to work in times and spaces completely different from those in which it was written. This work intends to analyze how this "genre" of translation, by updating the performative powers of such texts, ends up echoing an ethical-aesthetic dimension present in the assumptions of a certain criticism described by Walter Benjamin in The Concept of Art Criticism in German Romanticism.
\end{abstract}

KEYWORDS: Translation; Theater; Performativity; Iterability 
Em entrevista recente, o diretor Aderbal Freire-Filho, ao responder a uma pergunta sobre a tradução que havia feito para a peça $A$ paz perpétua $(2016)^{1}$, do espanhol Juan Mayorga, chama atenção para as complexas relações que configuram a autoria no que tange à poética do texto teatral. Pensando a dimensão da encenação, Freire-Filho afirma que nos textos escritos para o teatro, a autoria remete necessariamente a uma parceria entre o autor da peça e o diretor que a montará. A complexidade aí apontada se vê aprofundada no caso dos textos traduzidos, uma vez que o tradutor também atuará como operador dos processos de sentido que resultarão no espetáculo a ser apresentado. A importância desse terceiro partícipe aparece de forma exemplar em comentário feito por Angela Leite Lopes (2013). Ao falar sobre sua tradução da peça Incêndios ${ }^{2}$, do libanês radicado no Canadá Wajdi Mouawad, a tradutora explica que em seu processo de trabalho, a tradução final, aquela que servirá de base à montagem de determinado diretor, passa por várias versões até encontrar sua forma última. Isso se dá pelo fato de que, para ela, a tradução deve ser "testada" em leituras em voz alta, devolvendo ao texto seu aspecto propriamente teatral. As reflexões de Lopes e Freire-Filho ecoam o que nos diz Susan Bassnett sobre os diferentes processos tradutórios envolvendo o drama em relação a outros gêneros. Ao pensar o teatro como processo coletivo de criação, Bassnett $\left(2001\right.$, p. 100) ${ }^{3}$ afirma que

Traduzir para o teatro não é como traduzir poesia ou narrativa; não é, e não deve ser, um trabalho solitário. A natureza colaborativa do teatro significa que idealmente o tradutor deve estar engajado no processo, assim como o resto do conjunto.

Ou seja, para que a tradução do texto de teatro não perca de vista suas especificidades, não poderíamos afastar seu caráter performativo, incluindo nesta todos os elementos de ordem cênica que a atravessarão.

Essas questões nos remetem ao que Roland Barthes denomina como teatralidade em alguns de seus artigos. Em "Literatura e Significação" (Barthes, 2002b), o crítico francês tateia esse conceito a partir de uma tentativa de constituição de uma ontologia do próprio teatro. E essa estratégia é explicitada pela obviedade da pergunta com que inicia sua argumentação: "O que é o teatro?". Ao que o próprio autor responde ser o teatro "uma espécie de máquina cibernética (uma máquina de emitir mensagens, de comunicar)" (2002b, p. 508). O que Barthes (2002b, p. 508) nos faz notar, e aí estaria a especificidade do

\footnotetext{
${ }^{1}$ Essa tradução foi a utilizada por Aderbal Freire-Filho em sua montagem da peça de Mayorga no Brasil, cuja estreia aconteceu no dia 22 de outubro de 2016 no teatro Oi Futuro do Flamengo, Rio de Janeiro. A versão impressa foi, porém, publicada pela editora Cobogó ainda em 2015.

${ }^{2}$ A tradução de Lopes também foi utilizada em uma montagem dirigida por Aderbal Freire-Filho. Depois de participar de alguns festivais pelo Brasil, a estréia nacional de Incêndios aconteceu no dia 20 de setembro de 2013 no teatro Poeira, em Botafogo, Rio de Janeiro. Assim como a peça de Mayorga, a editora Cobogó também publicou a tradução da peça de Mouawad.

${ }^{3}$ Todas as traduções são de minha autoria.
} 
teatro, é que as mensagens enviadas ao espectador recorrem a diferentes sistemas de signos "vindos do cenário, do figurino, da iluminação, do lugar dos atores, de seus gestos, de suas mímicas, de suas falas [...]". Emitidos em ritmos e dispostos em temporalidades diferentes, o conjunto destes signos formaria, ainda segundo Barthes (2002b, p. 508), "uma verdadeira polifonia informacional", a qual ele chamará de teatralidade, caracterizando-a finalmente como uma "espessura de signos".

Escritas em 1963, essas reflexões fazem eco às formulações que o crítico já havia feito em 1954, em um texto intitulado "O Teatro de Baudelaire" (BARTHES, 2002a). Nele, Barthes (2002a, p. 304) afirmava ser a teatralidade um aspecto importante para se pensar o teatro baudelairiano ${ }^{4}$, definindo-a novamente a partir da mesma estratégia retórica que usará anos mais tarde para definir o teatro: "O que é a teatralidade? é o teatro menos o texto, é uma espessura de signos e sensações que se edifica sobre a cena a partir do argumento escrito". Ligando a polifonia informacional a uma "espécie de percepção ecumênica dos artifícios sensuais" (BARTHES, 2002a, p. 304-305) que caracterizaria essa mesma teatralidade, Barthes (2002a, p. 304-305) explica que esta, a despeito de sua manifestação na cena do espetáculo, "deve estar presente desde o primeiro germe escrito de uma obra", concluindo daí que "Não há grande teatro sem teatralidade devoradora [...]". O que ele nos faz notar é que a "polifonia informacional" que comandará a cena, colocando o texto a serviço da performance, já está, a princípio, inscrita no movimento de escrita das grandes peças.

Deixando a problematização dessa categoria - "grande teatro" - de lado, o que me interessa aqui é retomar a questão da tradução das obras dramáticas a partir dessas mesmas considerações feitas por Barthes. Ou seja, recuperando o comentário de Angela Leite Lopes sobre suas traduções de textos dramatúrgicos, é preciso considerar a teatralidade como aspecto determinante para a eficácia desse processo. Eficácia, aliás, que aparece aqui ligada à ambiguidade da própria noção de performance, abrindo-se ao mesmo tempo tanto para a encenação pura e simples quanto para a avaliação de seus resultados. Isto, claro, menos por seu viés judicativo a partir de valores normativos que pelos resultados práticos estabelecidos a partir das decisões específicas referentes a cada montagem.

\footnotetext{
${ }^{4}$ Reproduzo aqui a nota de Barthes referente ao teatro de Baudelaire (2002b, p. 304): "Conhecemos quatro projetos de teatro de Baudelaire. O primeiro, Ideal (ou Manoel) é um drama inacabado, em alexandrinos, escrito por volta de 1843 (Baudelaire tinha vinte e dois anos), em colaboração com Ernest Praron. Os três outros projetos são roteiros: $L a$ Fin de Don Juan não passa de um começo de argumento; Le Marquis du $1^{\text {er }}$ l houzards é uma espécie de drama histórico: Baudelaire deveria pôr em cena o caso do filho de um emigrado, Wolfgang de Cadolles, atormentado entre as ideias do seu meio e o seu entusiasmo pelo Imperador. L'Ivrogne, o mais baudelairiano desses roteiros, é a história de um crime: um operário, bêbado e indolente, mata a mulher atirando-a em um poço que ele cobre em seguida de pedras; o drama devia desenvolver a situação indicada no poema "Le Vin de l'Assassin", de Fleurs du Mal."
} 
Porém, surge aqui um deslocamento dessa relação entre texto e teatralidade que, acredito, só pode ser pensado ao restabelecermos o diálogo com a noção de autoria coletiva indicada por Aderbal Freire-Filho a que aludi anteriormente. Ou seja, nas traduções, a teatralidade que havia comandado a escrita da peça deve, para que o texto não perca sua eficácia em seu diálogo com os possíveis dispositivos semióticos que implicarão sua encenação, reatualizar seus princípios a partir de um diálogo implícito com a própria cena contemporânea em que se dará a ver. Dessa forma, é preciso que o original deixe de obsedar os resultados nos quais se verá conformado o texto - e aqui insisto novamente na noção de eficácia -, possibilitando a inscrição da tradução em um claro contexto pragmático, devedor de determinadas escolhas estéticas nas quais se daria a enunciação das falas. O tradutor, replicando o gesto do autor - sem, todavia, imitá-lo -, se vê diante da tarefa de recriar seu texto a partir de determinada cartografia cênica, única maneira de que seu ele se deixe devorar pela teatralidade necessária, gerando, assim, as condições mínimas para sua performatização ${ }^{5}$.

\section{SOBREVIDA E ITERABILIDADE COMO PRINCÍPIOS PERFORMÁTICOS}

A operação descrita acaba por evocar a condição iterável (DERRIDA, 1972) particularmente sensível nos textos teatrais, os quais devem colocar literalmente em cena a potência citacional que os mobiliza desde o princípio. Ou seja, trata-se de pensar a operação teatral a partir "da lógica que associa repetição a alteridade" (DERRIDA, 1972, p. 375), permitindo, desse modo, que os textos continuem a funcionar enquanto teatro em tempos e espaços completamente distintos daquele em que a peça foi redigida. Tal condição é que garante, evidentemente, que a peça se inscreva em um jogo atualizado de sentidos "na ausência absoluta do destinatário ou do conjunto empiricamente determinável de destinatários" (DERRIDA, 1972, p. 375) presentes em certo horizonte ideal de sua produção inicial ${ }^{6}$.

\footnotetext{
${ }^{5}$ Bassnett (2011, p. 100) cita o exemplo do diretor Peter Brook como exemplar nesse sentido. Segundo ela, essa atenção ao caráter eminentemente coletivo do processo explicaria "o sucesso do teatro de Peter Brook (...), no qual escritores e tradutores não trabalham isolados.

${ }^{6}$ A negação desse processo remeteria a uma espécie de a-historicidade da peça ao inscrever o que seriam seus sentidos transcendentais como a própria garantia de sua efetivação enquanto teatro, pouco importando as especificidades culturais da plateia para a qual seria apresentada. Talvez resida aí uma espécie de senso-comum sobre a ideia mesma da categoria de "clássico" como aquilo que não envelhece, menos por seus poderes de atualização que por sua capacidade de repetir verdades eternas e universais. Tal concepção é o que parece explicar a frustração de um espectador presente a uma apresentação do Hamlet proposto pela Armazém Companhia de Teatro, em julho deste ano, no CCBB do Rio de Janeiro. Sem reconhecer o que, como acreditava, devesse ser uma montagem "fiel" ao espetáculo concebido por Shakespeare, o espectador terminou por se queixar do que seria uma falha dessa máquina do tempo que o deveria levar de
} 
No caso das traduções, trata-se de retomar o gesto escritural que inaugura o próprio processo de encenação ao recolocar em jogo os mecanismos essenciais à sua poética, devedores, evidentemente, de sua performatividade. Para isso, o texto deve servir menos a um desejo de transmissão de um conteúdo fechado que atualizar suas potências propriamente dramáticas, acabando por ecoar uma dimensão ético-estética presente nos pressupostos de certa crítica descrita por Walter Benjamin em A Ideia de Crítica de Arte no Romantismo Alemão (2002). Em seu estudo sobre o primeiro romantismo alemão, protagonizado sobretudo por Friedrich Schlegel e Novalis, Benjamin (2002, p. 75) explica que "Essa crítica de arte [...] irá completar a obra, rejuvenescê-la, configurá-la novamente".

Isto posto, é preciso atentar para o fato de que não parece mais plausível sustentar aqui os pressupostos que ligariam esse pensamento a uma teleologia comandada pela noção de Absoluto. Segundo Márcio Seligmann-Silva (1999, p. 64), o regime estético no qual os românticos elaboram suas reflexões, "afirma a possibilidade de cada artista e cada obra, individualmente, traçarem o caminho para o Absoluto: cada obra é um medium-de-reflexão, um membro que constitui esse Absoluto". A noção de Absoluto estaria, assim, ligada à de Ideia da arte, tendo a crítica o papel de expor "a ligação da obra única com a Ideia da arte e, deste modo, com a Ideia mesma da obra singular" (BENJAMIN, 2002, p. 79). O problema que essa teorização evoca é a de um valor prévio que estaria presente nas "grandes obras", o que seria reconhecido desde o princípio pela crítica. Segundo Benjamin (2002, p. 85-86), para os românticos, "a valoração é imanente à pesquisa objetiva e ao conhecimento da obra. Não é o crítico que pronúncia esse juízo sobre ela, mas a arte mesma [...]", ao que o filósofo concluí que "Ao menos, se no âmbito da estética a duração histórica da validade das avaliações fornece um índice daquilo que sensatamente só pode ser denominado de sua objetividade, a validade dos juízos críticos dos românticos foi confirmada".

Deixando-se novamente de lado os problemas que essa posição traz para as questões relativas à conformação do cânone - "grande obra", "grande teatro" -, a economia temporal que comanda essa operação de transformação da obra não parece, todavia, perder sua validade. Assim, mesmo desviando-se de qualquer metafísica do absoluto como ponto de convergência e horizonte do processo crítico, podemos pensar na validade do que Benjamin explicitará como procedimento da própria história da arte para além do contexto dos românticos alemães. Em um fragmento ligado à preparação de "A obra de arte na era da reprodutibilidade técnica", ele faz a seguinte afirmação:

volta ao Globe Theater da virada dos séculos XVI e XVII, onde o ator e dramaturgo inglês encenou muitas de suas peças: "Ora, vim aqui para ver um clássico". O problema, porém, seria ensinar-lhe, na breve duração da montagem, a também comportar-se como o público daquela época. Sem isso, é pouco provável que sua reclamação cessasse. Aliás, como nos lembra Bussnett (2011, p. 97-101), a própria ideia de um texto acabado, pronto para ser encenado, passa longe da realidade de produção de Shakespeare, pois que o resultado final do que se via era certamente devedor das intervenções dos atores com quem trabalhava. 
A história da arte é uma história de profecias. Ela pode ser escrita apenas a partir do ponto de vista do presente imediato, atual; pois cada período possui sua própria possibilidade nova e não transmissível de interpretar as profecias que a arte de épocas passadas guardou justamente para ela (BENJAMIN apud SELIGMANN-SILVA, 2005, p. 20).

Em diálogo com Benjamin, podemos pensar na profecia aludida acima como o imperativo de atualização ao mesmo tempo dos discursos sobre / da obra. E aqui se impõe a própria ideia de tradução, não apenas entre diferentes línguas, como também entre diferentes épocas. O tradutor profeta é aquele capaz de reinscrever a obra em um circuito histórico a partir de um interesse preciso do presente, permitindo que esta enuncie a boa nova - ainda que na perspectiva dos românticos, esse mesmo gesto pareça devolvê-la a uma atemporalidade própria do Absoluto. De qualquer forma, mantendo-nos no que aqui nos interessa, o próprio Schlegel atestou as relações entre crítica e tradução no que tange à economia de transformação das obras. No fragmento de número 287 da Athenäum, podemos ler: "Somente mostro que entendi um escritor quando sou capaz de agir dentro de seu espírito, quando sou capaz de, sem estreitar sua individualidade, traduzi-lo e alterá-lo multiplamente" (SCHLEGEL, 1997, p. 98). Ao colocar em simetria conhecimento e alteração, Schlegel acaba por afirmar a estreita proximidade entre crítica e tradução como operações de um mesmo regime de atualização dos textos. Isso implicaria retomar a pergunta que Jacques Derrida (2006) faz em sua leitura do célebre texto de Benjamin sobre a tradução ${ }^{7}$. Ao abordar a questão da sobrevida das obras, Derrida (2006, p. 36) alude ao fato de que "tal sobrevida dá um pouco mais de vida, mais que uma sobrevivência. A obra não vive apenas mais tempo, ela vive mais e melhor, acima dos meios de seu autor". Novamente, é preciso recuperar aqui a noção de autoria coletiva presente no fazer teatral. $\mathrm{O}$ caráter suplementar da tradução, tal como apontado por Derrida, inscreve-se, assim, como imperativo desse fazer, tendo em vista a multiplicidade que a figura do autor assume desde o princípio, destituindo qualquer origem plena vinculada às suas produções. Sem possibilidade de uma identidade a si nem na figura do original nem na promessa de redenção de uma solução final é que a pergunta de Derrida (2006, p. 34) a respeito da sobrevida das obras pode ser recuperada em toda sua radicalidade: "Dir-se-ia que uma abertura é assim feita em direção à dimensão performativa dos enunciados?".

\section{DIMENSÃO PERFORMATIVA DOS ENUNCIADOS E TEATRALIDADE}

No caso específico do texto dramatúrgico seria possível fugir dessa radicalidade? $\mathrm{Ou}$, ao contrário, trata-se de afirmar ainda mais a inscrição dos textos nessa dimensão performativa para que possamos pensar a questão de suas

\footnotetext{
${ }^{7}$ Refiro-me ao texto "A Tarefa do Tradutor" (2001).
} 
efetividades cênicas? Nesse sentido, tradução e adaptação acabariam por se revelarem essencialmente próximas, pois que o texto deixaria de lado qualquer relação com um conteúdo transcendental a ser recuperado pela cena para ser o campo de experiências estéticas que requerem uma intervenção direta em sua poética. É nisso que o teatro se separaria, inclusive, de qualquer redução a uma ideia de texto falado. Artaud (1993, p. 65), em artigo de 1938 no qual se propunha a pensar quais seriam, na época, as diferenças entre os teatros ocidental e oriental, acerta em cheio o cerne desse problema: “(...) se encerramos o teatro nos limites daquilo que aparece entre as réplicas, não conseguimos separar o teatro da ideia do texto realizado". Ou seja, no teatro, o que Derrida chama de uma "dimensão performativa dos enunciados" não poderia, no limite, funcionar fora da dimensão da teatralidade, relegando ao texto um papel dentro da "polifonia informacional" para a qual Barthes dirige nossa atenção. Assim, é preciso muito cuidado diante de um comentário como o de Jean-Louis Besson (2005, p. 711), para quem, "Uma tradução não copia o original [...], mas ela se esforça para seguir sua poética e sua dramaturgia". O próprio Barthes (2002a, p. 304) chega a afirmar, na passagem citada logo no início desse artigo, que a teatralidade "é um dado de criação, não de realização". Ora, haver teatralidade - e mesmo que isso seja um imperativo para Barthes - no texto teatral não significa conceder a este o poder absoluto sobre a teatralidade que comandará sua execução enquanto peça de teatro. Caso contrário, correríamos o risco, como bem percebe Artaud, de confundir a ideia de teatro com a de "texto realizado". Isso remete ao fato de que em última análise não existe teatro sem tradução ainda que a montagem se dê na mesma língua do original. O que quero dizer é que desde o princípio, já no ato de transposição da peça escrita para a cena há a necessidade de uma tradução intersemiótica que leve em conta a teatralidade não apenas "prevista" pelo texto mas também aquela elaborada pelos processos cênicos que guiarão sua efetiva execução. Não se quer, assim, defender um relativismo desenfreado diante dos textos, mas, antes, resgatar sua especificidade enquanto texto de teatro, parte integrante da "espessura de signos" que guiará sua dimensão performativa ${ }^{8}$.

Pensemos em uma experiência prática. Em 2016, a Companhia de Palhaços, grupo radicado em São Paulo, levou aos palcos o espetáculo Adeus

\footnotetext{
${ }^{8}$ Certamente, tal posição não está obrigatoriamente em acordo com a posição do conjunto de autores teatrais. Jean Genet, por exemplo, em sua peça Os negros (GENET, 1963), escreve um breve prólogo introdutório intitulado "Para representar Os Negros". Neste, Genet (1963, p. 10) faz uma série de indicações sobre como a montagem deve proceder, entre as quais a que se segue: "Sobre qual o tom a recitar: imitar bem os atores trágicos e, sobretudo, as atrizes trágicas francesas. E, mais importante, acrescentar a isto talento". Isto, porém, em nada altera as reflexões aqui expostas, uma vez que posições como a de Genet não propõe nenhuma intervenção teórico-crítica ao problema. São, no máximo, signos de um controle da teatralidade que pretensamente deveria comandar toda a cadeia produtiva da peça: da escrita do texto a sua execução, tudo deveria ser regido pelo dramaturgo. Sua posição não diferia muito da de outras escritores da época, casos de Sartre e Ionesco, o que acaba também por explicitar uma visão relativamente comum do papel do diretor diante de uma preponderância do texto e seu autor sobre todo o processo de encenação.
} 
Palhaços Mortos, adaptação realizada pelo diretor José Roberto Jardim para peça Um Trabalhinho para velhos palhaços ${ }^{9}$, de autoria do dramaturgo romeno radicado na França Matéi Visniec. Em entrevista sobre a peça, Jardim comenta o processo de montagem do espetáculo:

Por serem três velhos artistas questionando o que aconteceram [sic] na vida deles até aquele momento, exatamente esse foi também o olhar que eu quis colocar agora. Nós enquanto artistas, eu, José Roberto na direção, Academia de Palhaços enquanto proponentes e fazedores culturais. $\mathrm{O}$ que é que eles esperam e como esse mercado ou como o mundo artístico tá consumindo. Qual que é essa política cultural que acontece? Então, nesse lugar, a gente foi pondo todas as nossas inquietações dentro desse texto. Problematizando e reproblematizando mesmo o fazer artístico (JARDIM, 2016, [s.p.]).

O que Jardim nos explica é que o texto de Visniec, para tornar-se de fato espetáculo, deve integrar-se aos princípios estéticos reguladores da especificidade que sua montagem, em pareceria com a Academia de Palhaços, propõe. O resultado, longe de estabelecer uma desfiguração da peça do autor romeno caminha para a ratificação de uma lógica que visa a diferenciar a "tradução teatral" da "tradução de textos teatrais" (ZURBACH, 2007, p. 161-165), uma vez que esta última encerraria o texto nos limites da "monodia literária" (BARTHES, 2002 b, p. 508), sintagma cunhado por Barthes para distinguir justamente as operações semióticas da literatura e do teatro. Dessa forma, o texto de Visniec não perde sua realidade material, mas afasta-se de qualquer clausura que tentasse regulá-lo a partir da ideia de um original contendo em sua integralidade transparente a partitura dramática a ser transportada para o regime semiótico da cena. É a impossibilidade desse mecanismo que transforma o escrito em teatro propriamente dito, demandando sua efetivação a partir da necessária "dimensão performativa dos enunciados". Essa dimensão seria a única capaz de garantir o caráter iterável da peça ao possibilitar que esta continue a ser enunciada para além do seu momento de produção inicial. Ou seja, a condição de sobrevida se dá na mesma medida da perda de qualquer primazia de uma teatralidade original. Ao comentar a questão da origem em Derrida, Moysés Pinto Neto argumenta que:

A ideia de "original" depende naturalmente de um "texto presente a si", isto é, de um eidos ou da arkhê do texto que estaria "lá fora" dos intérpretes. É também o lugar do "nome próprio" do texto, da sua interpretação própria, literal, autorizada. No entanto, tal local não existe. $\mathrm{O}$ texto não existe fora de um contexto de interpretação. (2012, p. 406)

No caso do teatro, a cena surge como "contexto de interpretação", contexto este sempre por se perfazer a cada nova proposta de encenação, mas jamais

\footnotetext{
${ }^{9}$ No original : Petit boulot pour vieux clown. Há uma tradução dessa peça publicada pela editora É Realizações, feita por Pedro Sette-Câmara (Ver bibliografia).
} 
realizado como totalização dramática - sua teatralidade - prescrita pelo próprio texto isolado.

Na montagem da Academia de Palhaços, o dispositivo criado gira a partir da experiência da própria companhia, ligada ao incêndio que culminou com a destruição da Kombi-palco contendo parte importante do material com que realizavam seus espetáculos itinerantes. De Um Trabalhinho para velhos palhaços ao Adeus Palhaços Mortos atua a máquina cibernética capaz de dar aos signos a espessura requerida pelo teatro. Dessa forma, despedir-se dos palhaços mortos constituí o processo necessário para que o velho palhaço possa continuar a renovar-se em cena.

\section{REFERÊNCIAS}

ARTAUD, Antonin. "Teatro oriental e teatro ocidental". In: O teatro e seu duplo. Tradução Teixeira Coelho. São Paulo: Martins Fontes, 1993, p. 65-70.

BARTHES, Roland. "Le Théâtre de Baudelaire". In: Euvres Complètes II. 2002a. p. 304-310.

525.

. "Littérature et Signification". In : Euvres Complètes II. 2002b. p. 508-

BASSNETT, Susan. Reflections on translating. Ontario: Multilingual Matters, 2011.

BENJAMIN, Walter. A tarefa do tradutor. In: GAGNEBIN, Jeanne Marie (org). Escritos sobre mito e linguagem (1915-1921). Tradução Susana K. Lages e Ernani Chaves. São Paulo: Duas Cidades, Editora 34, 2011, p. 101-119.

. O Conceito de Crítica de Arte no Romantismo Alemão. Tradução Márcio Seligmann-Silva. São Paulo: Iluminuras, 1993.

BESSON, Jean-Louis. "Pour une poétique de la traduction théâtrale". In: Critique, $\mathrm{n}^{\mathrm{o}} 699-700,2005$, p. 702-712.

DERRIDA, Jacques. Torres de babel. Tradução Junia Barreto. Belo Horizonte: Editora UFMG, 2002.

. "Signature, Événement, Contexte". In: Marges de la philosophie. Paris : Éditions de Minuit, 1972 p. 365-393.

FREIRE-FILHO, Aderbal. Sobre Poética e Tradução. Diário do Nordeste, Fortaleza, 10 de out. 2016. Acesso em 20 jun. 2017. Disponível em: $<$ http://diariodonordeste.verdesmares.com.br/cadernos/caderno-3/sobre-poetica-etraducao-1.1639539>. 
GENET, Jean. Les Nègres. Paris: Gallimard, 1963.

JARDIM, José Roberto. Adeus Palhaços Mortos: entrevista [julho 2016]. Entrevistador: Cirley Ribeiro, 2016. Entrevista concedida à Rádio Cultura FM 103,3. Disponível em: <http://culturafm.cmais.com.br/cultura-agora/comediateatral-adeus-palhacos-mortos-problematiza-a-carreira-de-artista $>$. Acesso em 10 jun. 2017.

LOPES, Angela Leite. "Modos de Dizer". In: Questões de crítica. Rio de Janeiro, n. 60, 2013. Disponível em: <http://www.questaodecritica.com.br/2013/ 12/modos-de-dizer/\#more-4132> . Acesso em: 5 jul. 2017.

PINTO NETO, Moysés. "Traduzir a morte de Deus: a linguagem como transcriação". In: SOUZA, Ricardo Timm de; MELLO Ana; SANTOS Marcelo Leandro dos; FARIAS André; SILVA Camilla Gonzatto da (Org.). Literatura e Psicanálise: encontros contemporâneos. Porto Alegre: Dublinense, 2012, p. 398421.

SCHLEGEL, Friedrich. O dialeto dos fragmentos. Tradução Márcio Suzuki. São Paulo: Iluminuras, 1991.

SELIGMANN-SILVA, Márcio. O local da diferença. São Paulo: Ed. 34, 2005.

. Ler o livro do mundo. Walter Benjamin: romantismo e crítica literária. São Paulo: Fapesp/Iluminuras, 1999.

VISNIEC. Matéi. Um Trabalhinho Para Velhos Palhaços. Tradução Pedro SetteCâmara. São Paulo: É Realizações, 2012.

ZURBACH, Christine. "Da efemeridade das traduções teatrais". In: A tradução teatral: o texto e a cena. Lisboa: Caleidoscópio Edições, 2007, p. 161-165.

Rodrigo Ielpo RodrigoIelpo@gmail.com

Recebido em: 15/9/2017 Aceito em: 18/2/2018 Publicado em Abril de 2018 